\title{
A PRIMER ON \\ Management Control Structures
}

\author{
Carl Brewer \\ Sam Houston State University \\ Huntsville, Texas
}

Responsibility accounting assigns a manager to be responsible for the operation of each organization segment where control is desired. A key aspect of responsibility accounting is that the manager will be held responsible only for those matters which the manager can control. It is often assumed, as in this presentation, that the concept of responsibility accounting has been established within an organization.

It is the manager's task to insure that segment personnel perform in such a way that the goals assigned to the segment are achieved. To facilitate this task, the manager utilizes management control.

The definition of management control given by Anthony, Dearden, and Bedford will serve as a frame of reference in this discussion:

Management control is the process by which management assures that the organization carries out its strategies. ([1], p. 10)

The same authors relate strategies and goals by stating:

To coordinate organization activities in pursuit of goals, organizations develop strategies to indicate the path organization management wants followed to achieve [its] goals. ([1], p. 93)

Essentially, then, management control is concerned with the achievement of the organization's goals. To this statement could be added the phrase "... through the actions of people." The authors clearly intend that management (and, therefore, management control) can achieve the goals of the organization only through the efforts of the non-management and management people who work for the organization.

\section{Management Control Concepts}

Management control appears to consist, at least conceptually, of four elements:

1. Goals.

2. Actual performance data.

3. Comparison.

4. Action.

Journal of Business Strategies, Volume 7, Number 1 (Spring 1990) 


\section{Goals}

To be in control, management must know where an organization is headed. Questions of why an organization exists and what the organization is attempting to accomplish must be addressed. In different levels of an organization, various terms, such as goals, strategies, objectives, budgets, and standards, are used in addressing these questions. While the terms may vary, it is evident that the basic concept of something to be achieved is present at each level.

The term "goal" is used in the model which is presented. However, the term is intended to convey the concept of something to be accomplished - an aim. While it is recognized that organizations and segments do not have goals - only people have goals - the phrase organization goal is retained due to its common usage.

Goals are what should occur. Goals represent the target toward which an organization's efforts are directed. Further, this aim is intended to be applicable to any organizational level. Without this target, an organization will flounder.

It is critically important that the goal be measureable, either directly or indirectly, in some meaningful way. This is necessary because the goal will be used as the standard against which actual organization performance is measured. Additionally, measureable goals indicate what performance data needs to be accumulated for management control purposes.

The goals at the lower levels must support, and to an extent flow from, the goals at higher levels to achieve a coordinated effort among the various segments of an organization. The mechanics of implementing goals implies the need to have an appointed manager for each segment who will be responsible for achieving the goals of the segment over which the manager has control.

\section{Data}

To determine whether an organization or segment is progressing as intended, measurements of current performance by the organization (or segment) must be made. Data about actual performance, then, is a fundamental concept of control. Without such data, organizational performance is only conjecture and there is no quantifiable method to identify if goals have been, or are being, accomplished.

The actual performance data collected must relate to one or more measureable aspect of the goals of the organization or else the data is useless for management control purposes. Therefore, the organization (or segment) goals must be measureable in some way, either directly or indirectly via the use of surrogates. If the goals are not measureable then they are inoperable because data which would indicate if the goal is or was being achieved could never be gathered. In other words, the performance data which must be collected for management control purposes is determined by the goals which are being evaluated.

\section{Comparison}

A fundamental concept in management control is management's comparison of actual performance data against desired performance, as indicated by the standard 
set by the goal. The objective of this comparison is to identify performance which deviates significantly from the goal. This objective is complicated by two factors: the strength of the comparison and the significance of the deviation.

Strength of Comparison. Strength of comparison related to both availability of performance data and the measurability of the goal. Without data about actual performance that relates to the goal, comparisons cannot be made. Also, as the goal becomes less measureable, the comparison becomes less meaningful. Both of these aspects must be considered by the manager when evaluating deviations from the goal.

Significance of the Deviation. Deviation from the goal is the primary indicator of actual performance which does not conform to the goal. Determination of when a deviation, in absolute terms, is significant must be made only after considering the strength of the comparison being made. Even though significance relates to the degree of the deviation from the goal, determination by the manager of the significance of any given deviation is highly judgmental. Determination of whether a deviation is significant or not completes the two-phased analysis made in the comparison.

\section{Action}

Action is the most crucial phase of management control - without it there is no operable control. When significant differences exist between actual performance and the goal, action must be taken by the manager regarding those differences over which that individual has control. For most of those differences over which a manager does not have control, some other level of management will have control. In this case, it is the other manager who should take action. Further, it must be recognized that some of the differences may be imposed upon the organization by the external environment and not controllable by the organization.

An action will not be effective, however, and consequently there will be no management control, unless the action leads to a convergence of the goal and future actual performance. For management control to exist, whatever action is taken must result in the attainment of the goal. It may be that performance must be modified. Alternatively, it may be deemed that the goal is unattainable and must be changed. However, this second alternative should be extremely rare because changing an existing standard alters the basis of evaluating past performance.

\section{Implications}

The concepts presented above explain the basis for management control. In addition, they provide a reference scheme for designing management control structures and also for evaluating existing management control in an organization. Specifically, each concept - goals, data, comparison, action - must be present for management control to exist. Further, they must be present in each organizational segment where control is desired. Even in the most complex of organizations, the evaluation of management control can be resolved into a determination of whether or not these concepts are present and to what degree. 
In addition, the four concepts provide a useful classification of management control problems. Any management control problem can be categorized as a problem in one or more of the following: goal, data, comparison, or action. Once the type of problem is identified, correction is facilitated. For example, when faced with a management control problem as indicated by a manager being unable to meet an assigned goal, it is reasonable to ask whether the problem stems from an unreasonable goal, an unmeasureable goal, insufficient data, or inept management action.

\section{Management Control Structures}

The four control concepts can be symbolized by the management control structure presented in Figure 1. For management control purposes, each element must be present within any given segment of the organization where management control is desired. When evaluating management control in any given segment, each element must be evaluated.

\section{Figure 1}

Management Control Structure

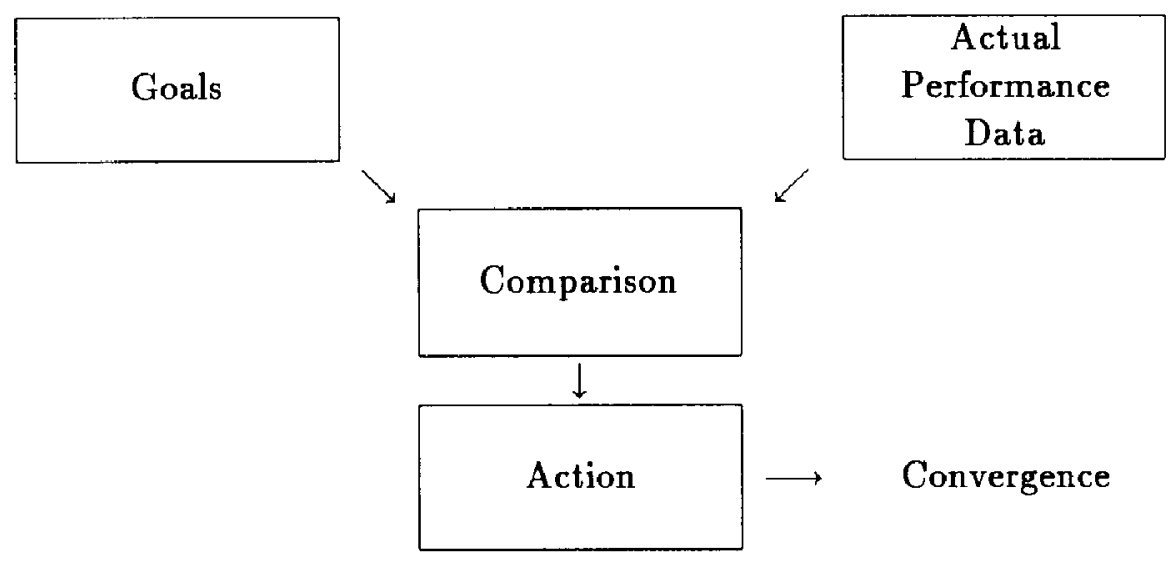

An organization can be depicted as a hierarchy of organization segments as illustrated in Figure 2. In accordance with responsibility accounting, each segment should have a manager assigned to it who will be responsible for the operation of the segment. In this capacity, it is the manager who is responsible for those aspects of the segment's operations which can be controlled at that level of the organization.

In designing a management control scheme within an organization, a management control structure must be embedded within each organization segment. This is graphically illustrated in Figure 3. In this way, it can be assured that at least the elements of control are present within the organization. Whether the control scheme operates as desired, however, is a different matter. The functioning of management control within the organization can be determined by evaluating each control element within each control structure embedded within each control segment. 
Figure 2

Simplified Organization Chart

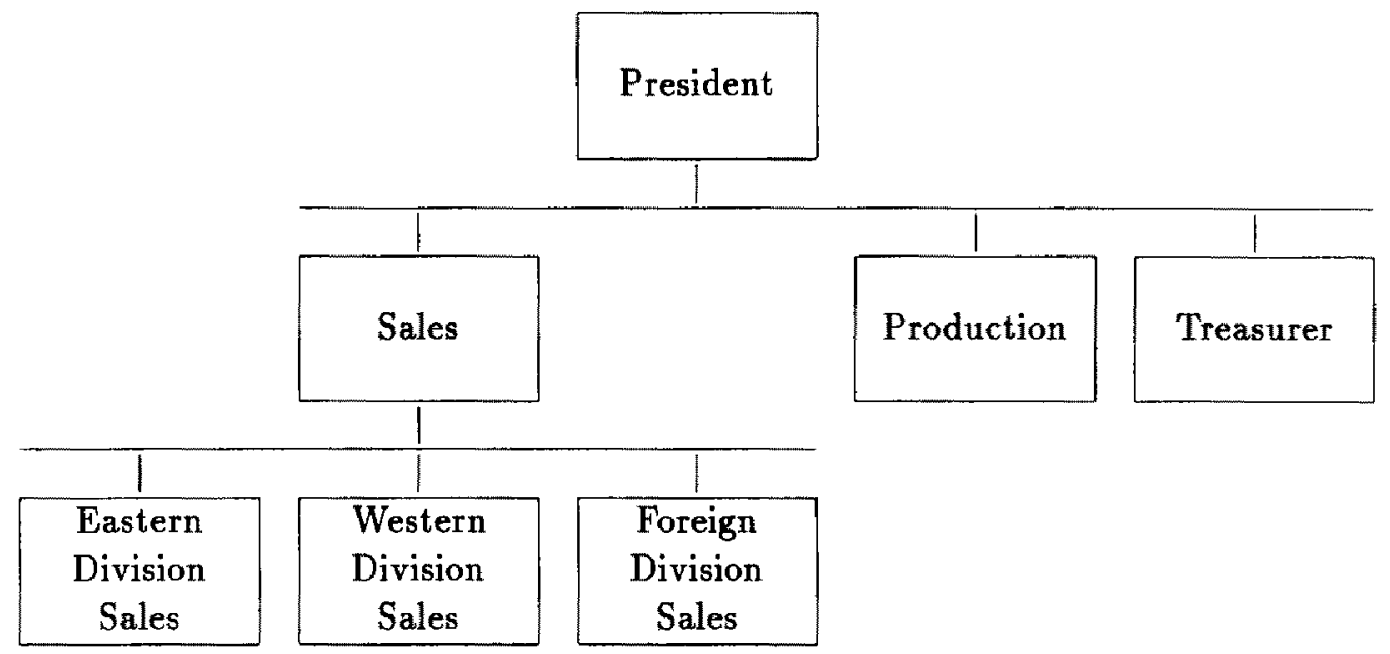

Figure 3

Management Control Structures Embedded within Organizational Segments

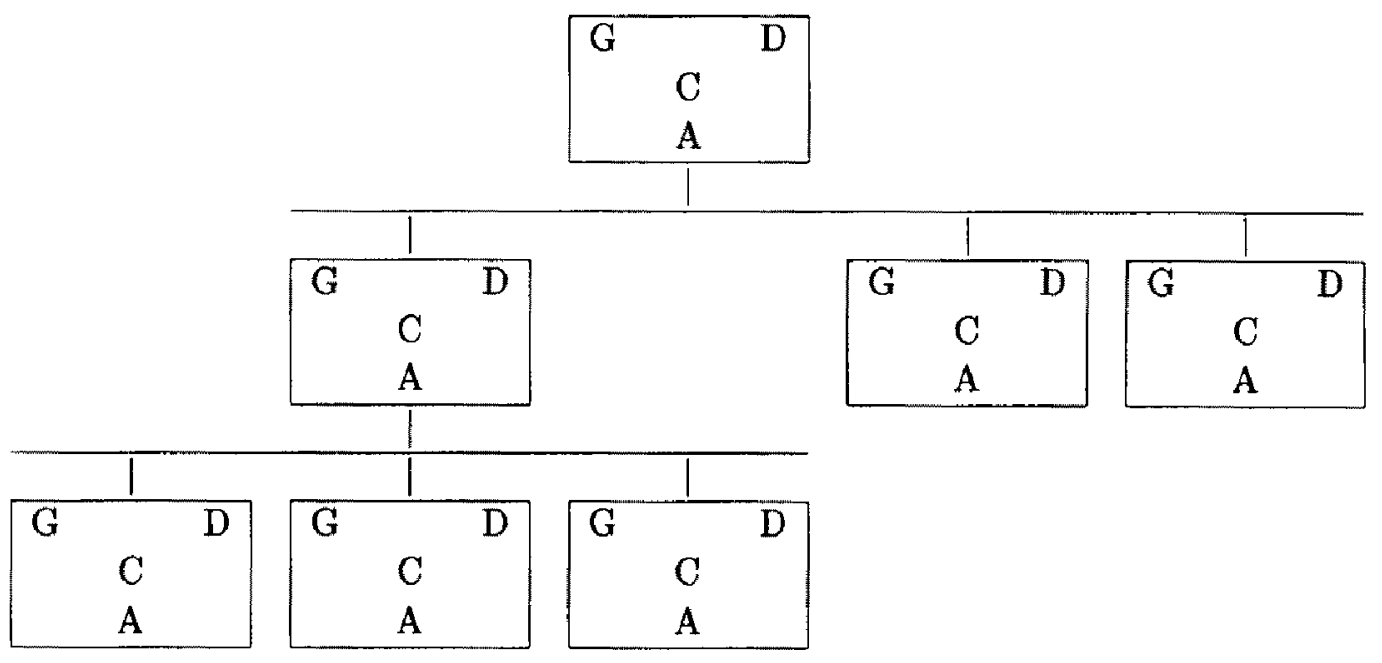

Additionally, there is a linking mechanism that should exist between echelons in the organization which should also be evaluated. Goals between echelons should be related and flow down through the hierarchy, as presented in Figure 4. Upper echelon goals will influence the goals set for a lower echelon within the same segment. Therefore, the goals of the President will influence the goals of Sales which, in turn, influence the goals of the Eastern, Western, and Foreign Divisions. This downward 
Figure 4

Linking Mechanism: Downflows of Goals

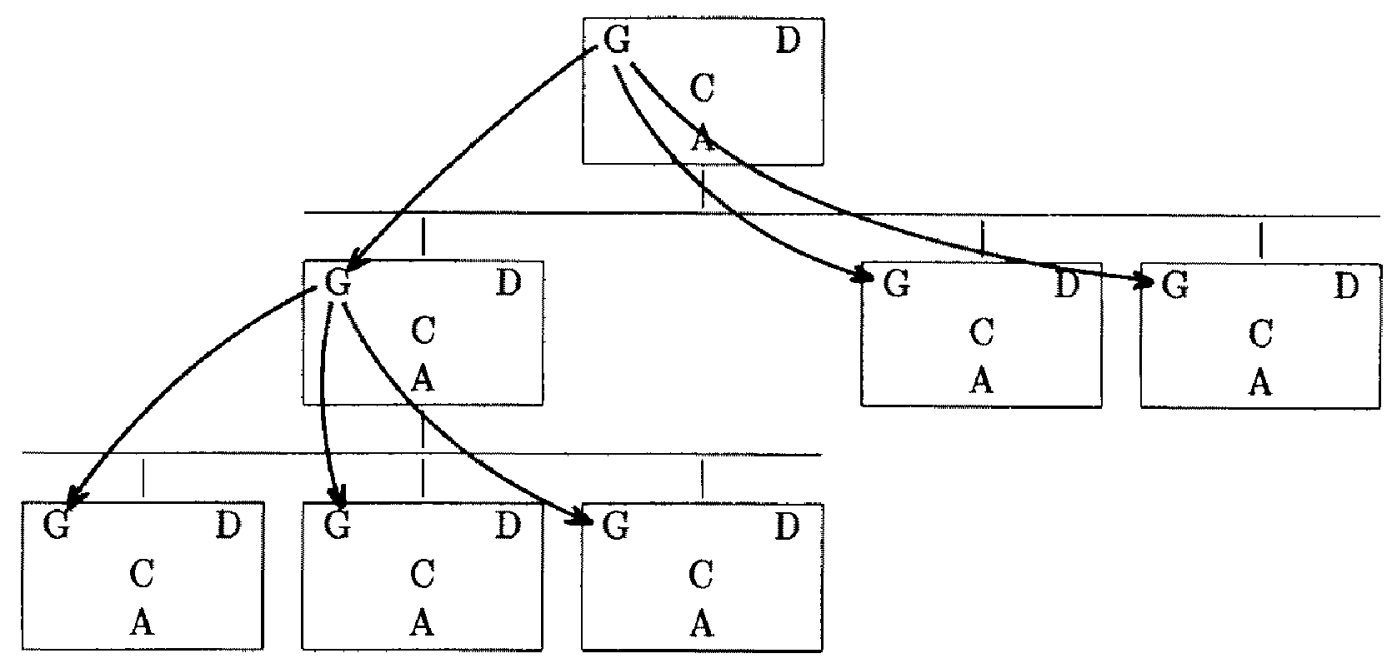

Figure 5

Linking Mechanism: Upflows of Data

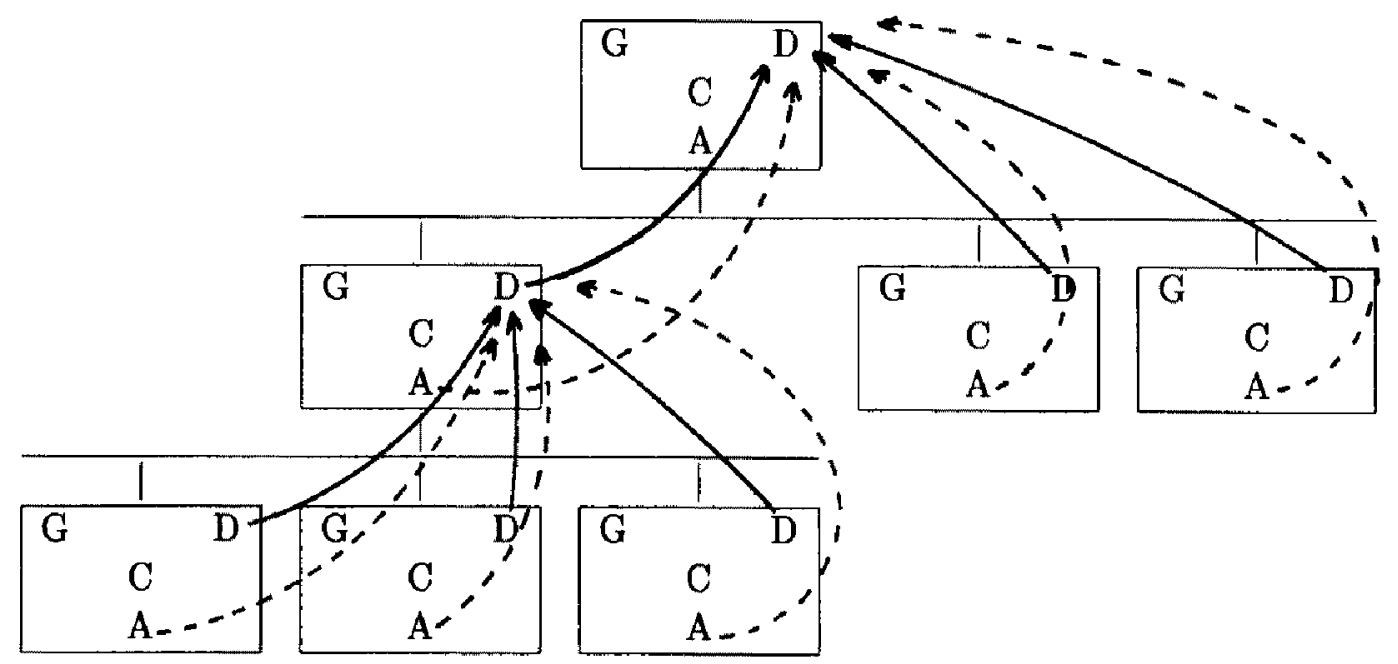

flow is similarly applied to each of the four elements for all subordinate levels within the hierarchy.

In a similar manner, there should be an upward linking for control. Information about action and performance (i.e., data) should flow back up the organization so that each higher level can review the performance of the lower levels. Figure 5 illustrates this upward flow path. 


\section{Environmental Factors}

How the management control elements are applied in any given organization will be influenced by several environmental factors, such as management style, the type of management information system, the informal organization, subordinate personnel behavior, the nature of the activity being controlled, or other factors. Environmental factors affect issues such as how goals are set, how evidence about performance is gathered, how action is accomplished, and how frequently these activities are reviewed or occur within the organization.

Environmental factors are not discussed in detail since they do not alter in any fundamental way the basic elements of management control.

\section{Summary}

The concepts of goal, data, comparison, and action are applicable to any organization level, including the overall organization. No matter what organization segment is under consideration, each of these concepts must be present or else control is absent or deficient.

Also, the concepts are applicable to any type of organization - product, service, profit, not-for-profit, or governmental. Management control is the process which assures the attainment of the organization's goals. For the concept of management control to be operative in an organization, the organization must articulate its goals. If any organization, regardless of type, articulates its goals, a functioning control scheme can be designed and effectively utilized to enhance its operations.

\section{Reference}

1. Anthony, R. N., J. Dearden, and N. M. Bedford. Management Control Systems, fifth edition. Hinsdale, IL: Richard D. Irwin (1984). 